This item was submitted to Loughborough's Research Repository by the author.

Items in Figshare are protected by copyright, with all rights reserved, unless otherwise indicated.

\title{
Cellular PVC-U: current technology and future challenges
}

PLEASE CITE THE PUBLISHED VERSION

PUBLISHER

(c) Sage

LICENCE

CC BY-NC-ND 4.0

\section{REPOSITORY RECORD}

Thomas, Noreen L.. 2007. "Cellular PVC-U: Current Technology and Future Challenges". figshare. https://hdl.handle.net/2134/2888. 
This item was submitted to Loughborough's Institutional Repository by the author and is made available under the following Creative Commons Licence conditions.

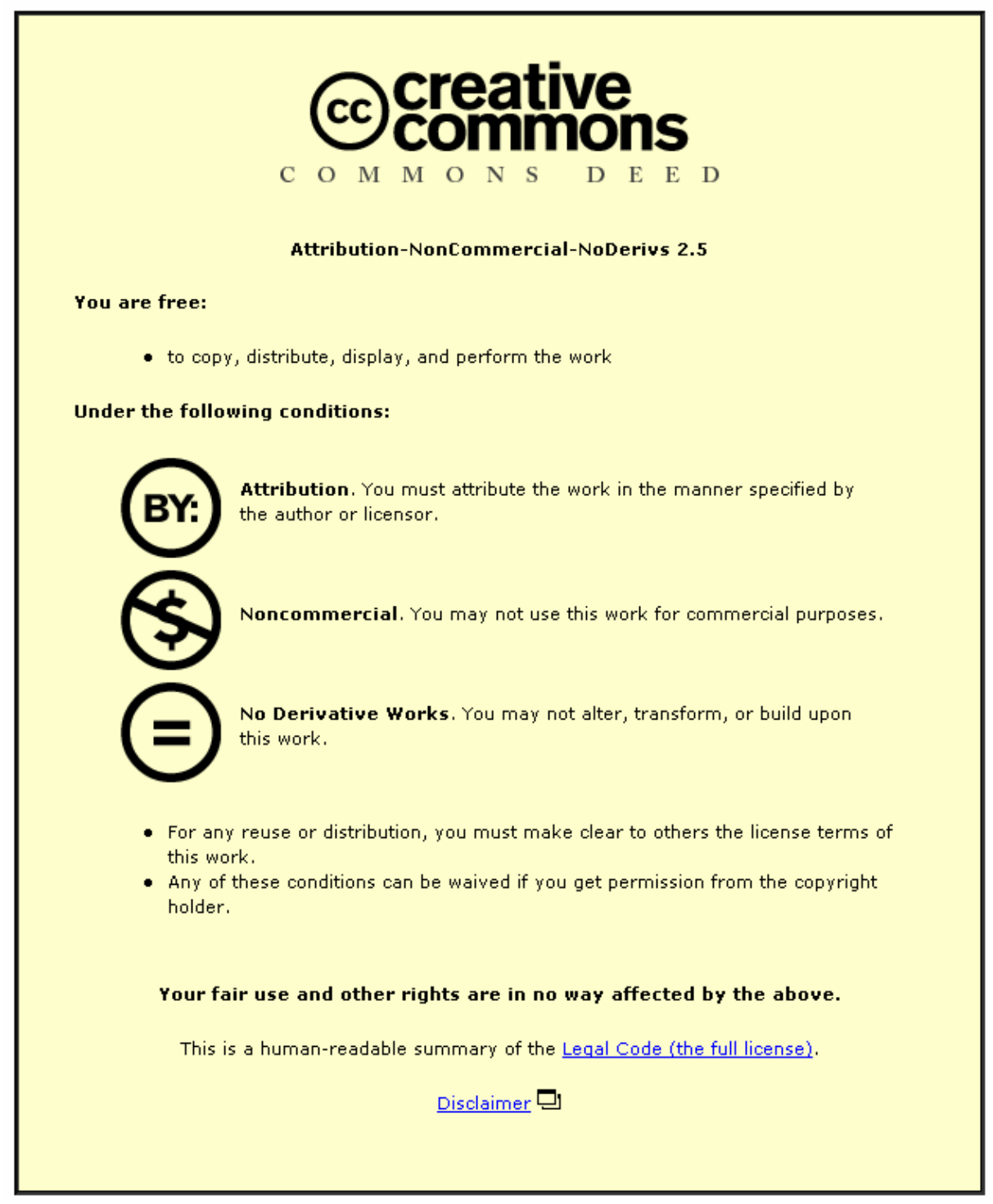

For the full text of this licence, please go to: http://creativecommons.org/licenses/by-nc-nd/2.5/ 


\title{
Cellular PVC-U: Current Technology and Future Challenges
}

\author{
N. L. Thomas \\ Institute of Polymer Technology \& Materials Engineering, Loughborough \\ University, Loughborough,Leicestershire,LE11 3TU, UK. \\ N.L.Thomas@lboro.ac.uk, Tel: +44(0)1509 223334
}

\begin{abstract}
This paper discusses the formulation technology involved in the production of rigid PVC foams and typical formulations for rigid foam sheet and profile are presented. Particular reference is given to acrylic processing aids and their effect on melt extensibility and strength. Measurements carried out using an elongational rheometer have confirmed that melt extensibility and rupture stress are increased with increasing addition level and/or molecular weight of the processing aid used.
\end{abstract}

The challenges facing the PVC foam industry and also addressed. These include environmental issues, such as the need to develop formulations with sustainable additives and to increase recycling of PVC products. Future developments include the use of organic-based stabilisers (OBS) and the use of nanofillers.

This paper was presented as an invited contribution at the $8^{\text {th }}$ International Conference on 'Blowing Agents and Foaming Processes 2006' on $16^{\text {th }}-17^{\text {th }}$ May 2006, Munich, Germany, organised by Rapra Technology.

Key Words: Cellular, Foam, PVC-U, Poly(vinyl chloride), Processing aid, Melt strength

\section{INTRODUCTION}

PVC (poly(vinyl chloride)) is a commodity thermoplastic polymer with the third largest tonnage after LDPE and PP. In 2005 global PVC production was about 27 million tonnes. The industry is not only important because of polymer supply and its role in the chlor-alkali business, but also in terms of additive producers, compounders, product manufacturers and end-users. PVC is a uniquely versatile polymer that is used in a large range of applications in many industry sectors. Applications include potable water pipes, window frames, guttering, credit cards, food packaging, medical tubing and blood storage bags. The versatility of PVC is due to its compatibility with many additives, including plasticisers, heat stabilisers, lubricants, fillers and other polymers. The success of PVC is perhaps surprising as it is one of the least stable polymers, for which reason much of the early development was concerned with copolymers and with plasticised compounds. However, the reason for the success and versatility of PVC is the complex formulation technology that has been developed.

The useful processing window for any polymer lies between the melting point of the polymer and the onset of thermal degradation. As a rule of thumb, this requires that the degradation temperature is at least $30^{\circ} \mathrm{C}$ above the crystalline melting point for crystalline polymers, or at least $150^{\circ} \mathrm{C}$ above the glass transition temperature for amorphous polymers. Table 1 shows a list of common polymers together with their glass transition temperature $(\mathrm{Tg})$, crystalline melting point ( $\mathrm{Tm}$ - if appropriate) and approximate degradation temperature (Tdeg). The important point to note from this table is that the melting point of the $10 \%$ crystalline component of PVC is above its maximum processing temperature of $200^{\circ} \mathrm{C}$. The processing temperature of PVC must be restricted to $200^{\circ} \mathrm{C}$ or below to prevent thermal degradation. PVC never achieves a true melt state. Standard processing temperatures (typically between $180^{\circ} \mathrm{C}$ and $200^{\circ} \mathrm{C}$ ) are not high enough to melt all the crystallites. The polymer becomes 'fused' or 'gelled' into a homogeneous mass suitable for extrusion or calendering.

Thermal degradation of PVC is largely due to the evolution of hydrogen chloride, resulting in long sequences of conjugated polyenes, as illustrated in Figure 1. The elimination of hydrogen chloride molecules in sequence along the polymer chain is known as an 'unzipping reaction'. The extent of degradation can be judged by the colour change of the PVC sample. Colour change will vary through a sequence of colours from white to cream to yellow to orange to red to brown to black, with increasing degradation. 
The process of gelation involves softening, deformation and adhesion of the PVC particles. Its rate depends on the softening behaviour of the polymer, the rate of heating by externally applied means and frictional heating from applied shear in an extruder or injection moulding machine. Important studies on the mechanism of fusion or gelation of PVC were first carried out by Allsopp[1] and also by Summers [2]. It is recognised that melting and recrystallisation of a proportion of the primary crystallites is important in forming a network held together by tie molecules and secondary crystallinity. Figure 2 shows a schematic diagram of the fusion process, based on the model due to Summers. Primary particles of PVC are shown in Figure 2A, which consist of primary crystallites and amorphous macromolecules. During processing, under the influence of both heat and shear, there is partial fusion of the crystallites and diffusion of macromolecules (Fig 2B). During the cooling stage (Fig $2 \mathrm{C}$ ) recrystallisation occurs and the secondary crystallites help to link the primary particles together, so that the original particle boundaries have disappeared.

\section{FOAM FORMULATION TECHNOLOGY}

As in all PVC applications, the formulations for the production of foamed PVC are a complex mixture of thermal stabilisers, lubricants, processing aid, pigment and filler, in addition to the blowing agents required to produce the cellular structure. The type of PVC and formulation ingredients control the thermal stability, gelation behaviour, powder flow characteristics, melt viscosity and melt strength of the material during the production process. Hence all the components of the formulation will influence the subsequent foam density, surface finish and overall properties of the foam and there may be interactions between individual ingredients.

\section{Rigid Foam Sheet}

Table 2 shows a typical formulation for PVC free-foam sheet $[3,4]$. Some of the important ingredients in this formulation will be discussed below.

Organotin stabilisers are usually used for these products. In PVC foam formulations stabilisers perform a dual role [5]: not only do they prevent thermal degradation of the polymer but they may also activate the decomposition of the chemical blowing agent azodicarbonamide (ADC). Organotin stabilisers can be divided into two types: mercaptides and carboxylates. The majority of tin stabilisers used are mercaptides. They are cheaper than carboxylates and give excellent heat stability but poor weatherability. Also they do not act as 'kickers' for ADC decomposition. Hence formulations based on tin mercaptide, which are used for the majority of non-weathering foam sheet products, require 'kickers' for ADC decomposition: otherwise a low gas yield will result. Tin carboxylates are more expensive than tin mercaptides but offer excellent weathering properties and do activate ADC decomposition. These stabilisers are a good choice for free-foam sheets for outdoor applications

Lubricants are needed in the processing of PVC to improve surface finish and control rheology. There are two broad classes of lubricants, known as 'external' and 'internal' lubricants. External lubricants reduce adhesion between the molten PVC and the metal processing equipment, prevent over-heating and reduce melt pressure. Compounds typically used as external lubricants are low melting point waxes and compounds with low solubility in the polymer. Examples are hydrocarbon waxes (paraffin wax and low molecular weight PE wax) and stearic acid. Internal lubricants have the role of reducing melt viscosity and also promote fusion. These are compounds that are compatible with PVC. Examples of internal lubricants are amide waxes, glyceryl esters and long chain alcohols and esters.

Lubricants are important in the foam extrusion process: it is essential that the PVC blend gels early enough in the extruder, so that gases generated from the chemical blowing agent can dissolve in the melt and are not drawn off in the vent or even lost back up the hopper. Also it is essential to generate enough shear to decompose the blowing agent. However, too much shear heating will cause cell collapse. Hence a balance of internal (compatible) and external (incompatible) lubricants is required.

The blowing agent of choice for free-foam sheet is azodicarbonamide (ADC). It has the structure $\mathrm{H}_{2} \mathrm{~N}-\mathrm{CO}$ $\mathrm{N}=\mathrm{N}-\mathrm{CO}-\mathrm{NH}_{2}$ and decomposes exothermically at about $215^{\circ} \mathrm{C}$ to give a gas yield of $220 \mathrm{~cm}^{3} / \mathrm{g}$. The major gaseous decomposition product is nitrogen, which constitutes about $60 \%$ by volume of the gases evolved. Activators or 'kickers' are required to bring the decomposition temperature of ADC down into the processing temperature window for rigid PVC foams $\left(170-190^{\circ} \mathrm{C}\right)$ but, as discussed above, many thermal stabilisers for PVC perform this function. ADC has the advantage of being a highly efficient exothermic blowing agent, which gives a high rate of gas expansion and a fine, uniform cell structure. 
The typical density distribution across a section of PVC free-foam sheet is shown in Figure 3. It is seen that there is an even foam density of about $500-600 \mathrm{~kg} / \mathrm{m}^{3}$ with a thin higher density skin [6].

Figure 4 shows a scanning electron micrograph of the foam structure of a through thickness cross-section of a sample of free-foam sheet [4]. This has a fine, even, closed cell morphology, which was produced using azodicarbonamide as blowing agent. The fine cell structure gives good surface properties for this type of foamed product.

Typical uses of PVC foam sheet are display panels, signs, advertising boards, partition panels, building panels, garage door panels, table tops and shelves. It has the advantage of being suitable for printing and painting, and of course can be pigmented. Sheets can be thermoformed, even after printing, and this opens up an even wider range of possible applications.

\section{Rigid Foam Profile}

Rigid PVC foam profile is mainly used for wood-replacement products [3, 4]. It is particularly useful because of its good weatherability and therefore many applications are for exterior use. Examples of exterior applications include cladding, soffit boards, roofing products, windowsills and door-frames. Examples of interior applications are skirting boards, cornices, wall and ceiling panelling, curtain rails, guide rails for shutters, coving and furniture profiles.

A typical formulation for PVC-U foam profile is given in Table 3. Lead based stabilisers are still widely used in Europe, although, as discussed below, the industry is now responding to environmental pressure to move away from lead-based stabilisers. New formulations are now being adopted based on calcium stearate and zinc stearate, or calcium stearate and zinc laurate. Generally $\mathrm{Ca} / \mathrm{Zn}$ stabilised formulations have a smaller processing window than those based on lead and thermal stability is not as good, but improvements are being made all the time.

The best blowing agent to use for rigid foam profile is a mixture consisting of mainly sodium bicarbonate $(90 \%)$ with a small amount of azodicarbonamide $[7,8]$. Sodium bicarbonate (SBC) decomposes to give $\mathrm{CO}_{2}$, $\mathrm{H}_{2} \mathrm{O}$ and $\mathrm{Na}_{2} \mathrm{CO}_{3}$. The reaction is endothermic and reversible and takes place over a wide temperature range, which includes the processing window of rigid PVC foam. The gas yield is only $125 \mathrm{~cm}^{3} / \mathrm{g}$ and compared with ADC the decomposition is slow and erratic, and a coarse cell structure is obtained $[7,8]$. However, the advantages of SBC are that it is easier to handle than ADC (which is classed as an irritant), it produces a whiter foam and is less prone to give problems with cell collapse. Combining SBC with ADC ensures a reasonably fine cell structure but avoids the problem of cell collapse.

Most foam profile is extruded using the Celuka method $[3,4]$, also known as the inward foaming process. In this method the calibration unit is situated adjacent to the die and has the same dimensions as the die, thus controlling foam expansion. This set-up gives very rapid cooling. Bubble formation is quenched in the surface of the product and a solid outer skin is produced. Figure 5 shows the density distribution across the thickness of a Celuka profile. There is a solid outer skin, usually about $0.5 \mathrm{~mm}$ thick, and a lower density core. The outer surfaces of Celuka products are the same as those of solid extrusions.

Figure 6 shows a scanning electron micrograph of a cross-section through a Celuka profile. The solid outer skin can be seen on the right hand side of the micrograph. Also to the left of the centre of the picture is a vertical line corresponding to the join between the two melt streams that have been separated by the mandrel in the die. This line lies midway through the thickness of the profile and corresponds to the dip in density shown at the centre of Figure 5 . It is clear that this profile has a coarser cell structure than that of the free-foam sheet, but the solid skin confers better hardness and impact properties.

\section{Processing Aids}

Processing aids are added to PVC formulations to promote fusion, increase melt strength, improve resistance to melt fracture and improve gloss and surface finish. The most commonly used processing aids are based on high molecular acrylic polymers, which are highly compatible with PVC (eg PMMA or butyl acrylic/methacrylic ester copolymers). In formulations for rigid PVC foam there is no doubt that processing aid is an important ingredient: the improvement conferred in both melt elasticity and strength prevents collapse of the cellular structure.

It has been shown that both the concentration [9] and molecular weight [10] of the acrylic processing aid can give significant reductions in foam density and prevent collapse of the cellular structure. Hence a desired 
improvement in melt strength may be achieved either by use of a high level or high molecular weight of processing aid. Measurements carried out using an elongational rheometer have confirmed that melt extensibility and rupture stress are increased with increasing addition level and/or molecular weight of processing aid [11].

Figure 7 shows a plot of elongational stress versus Hencky strain i.e. In(draw ratio), for unmodified PVC compared with two formulations containing 8 and $12 \mathrm{phr}$ respectively of an acrylic processing aid. These tests were carried out on a Rutherford elongational rheometer at a temperature of $180^{\circ} \mathrm{C}$ and a test velocity of $0.045 \mathrm{~m} / \mathrm{s}$. Samples of PVC foam formulations (minus blowing agent) were prepared for this test by processing on a twin-roll mill at $165^{\circ} \mathrm{C}$ followed by compression moulding at $170^{\circ} \mathrm{C}$. In the deformation tests a temperature of $180^{\circ} \mathrm{C}$ was chosen to reflect the processing conditions most appropriate to the foaming phase in the extrusion of rigid PVC foam profiles. It is seen that addition of the acrylic processing aid gave an increase in both the extensibility and the rupture stress compared with the unmodified PVC control. The weight average molecular weight of this particular processing aid was $1.33 \times 10^{6}$.

Increasing the molecular weight of the processing aid allows equivalent improvements in the extensibility and rupture stress of the PVC to be made at lower addition levels. Figure 8 shows the effect of adding an acrylic processing aid with a weight average molecular weight of $3.77 \times 10^{6}$. An additional level of 8 phr of the higher molecular weight polymer achieves the same improvements as $12 \mathrm{phr}$ of the lower molecular weight.

The effect of molecular weight is compared directly in Figure 9, which shows a plot of elongational stress versus Hencky strain for the PVC control sample compared with two PVC formulations containing 8 phr of acrylic processing aid. One acrylic processing aid has a weight average molecular weight $\left(\mathrm{M}_{\mathrm{w}}\right)$ of $1.33 \times 10^{6}$, whereas the second has a value of $\mathrm{M}_{\mathrm{w}}$ of $3.77 \times 10^{6}$. The latter processing aid shows a clear benefit in terms of enhanced elongational strength. Note that the K-value of the PVC typically used for foam sheet and profile is in the range of $57-60$ and this corresponds to a value of $M_{w}$ of around 60,000 to 65,000 . This contrasts with the much higher molecular weight of the acrylic processing aids. The improvement in melt elasticity and strength afforded to the PVC samples by addition of acrylic processing aid is due to the increased molecular entanglements created by the longer chain acrylic molecules.

The influences of both concentration and molecular weight of processing aid on the density of extruded freefoam strip are shown in Figure 10 [11]. It can be seen that for all processing aids there is a reduction in foam density as the addition level is increased from 4 to $8 \mathrm{phr}$, although the effect is less evident at high molecular weights. The corollary is that a desired improvement in melt strength may be achieved either by use of high molecular weight or by high level of processing aid.

The importance of processing aid in PVC foam extrusion is illustrated by comparison of the scanning electron micrographs of Figures 11 and 12. Figure 11 shows the foam morphology of a low density foam with $8 \mathrm{phr}$ of acrylic processing aid. When the level of processing aid was dropped to $4 \mathrm{phr}$, there was evidence of cell collapse, as shown in Figure 12.

It is essential to optimise the formulation in terms of the balance between the level of blowing agent and processing aid in order to prevent collapse of the cellular structure.

\section{FUTURE CHALLENGES}

There is growing demand for rigid PVC foam in both Europe and the USA in the three market sectors of profile, sheet and foam core pipe. Many of the applications for PVC foam profile are for wood-replacement products because of its ease of fabrication and the advantages of a maintenance-free product. The formulation and process technology of rigid PVC foam have been well researched. These materials offer the attraction of providing optimum stiffness and strength for the minimum weight of material. Hence, there is a constant drive towards novel applications for PVC foam and also towards new ways of foaming solid products to improve cost effectiveness. There is certainly much opportunity for innovative, new products and the development of fresh markets.

One of the main challenges facing the PVC foam industry, as indeed many other industry sectors, is the need to take a pro-active stance towards environmental issues and to enhance its approach towards sustainable development. Understanding the challenges that must be met in order to achieve full sustainability for any material requires an appreciation of all the complex factors relating to ecological, social and economic sustainability. 
The PVC industry as a whole has taken a responsible and pro-active stance on environmental issues and undertaken voluntary measures embodied in the Vinyl 2010 sustainable development initiative (launched in 2001) that will make an important step towards sustainability for the industry. Vinyl 2010 has a pan-European scope and makes voluntary commitments with a 3-fold objective: to minimise risks to the environment and human health, to maximise recycling and recovery rates for PVC, and to realise socially responsible best practices. Full details of the Vinyl 2010 initiative and the annual Progress Reports are available on the Vinyl 2010 website [12].

The key actions from the Vinyl 2010 commitment that require materials research input are as follows:-

- A plan for full replacement of lead stabilisers by 2015 , in addition to the replacement of cadmium stabilisers that was achieved in March 2001

- The recycling in 2010 of 200,000 tonnes of post-consumer PVC waste

- A research and development programme on new recycling and recovery technologies

The challenges to replace lead stabilisers and to increase end-of-life PVC product recycling have an obvious impact on the formulation of rigid PVC foam.

\section{Replacement of Lead Stabilisers}

Thermal stabilisers based on $\mathrm{Ca}$ and $\mathrm{Zn}$ carboxylates have been under development for many years to replace lead phosphites, stearates and sulphates. However, they have not yet been widely adopted because not only are they are more expensive than lead-based stabilisers but they are not as effective and have a narrower processing window. However, now that there is a definitive commitment to remove lead stabilisers, foam extrusion companies have started moving to $\mathrm{Ca} / \mathrm{Zn}$ stabilisers.

Increasing awareness of the need to safeguard the environment has lead to the development of a new generation of stabilisers that do not require the presence of any zinc salts, even in catalytic amounts. This new class of stabiliser is based on uracil chemistry and these materials are known as 'organic based stabilisers' - OBS. The chemical structure [13] of the key compounds is illustrated below in Figure 13. These compounds are used together with co-stabilisers that act as hydrochloric acid scavengers.

So far the development of these compounds has been focussed on the pipe industry, but they are now being trialled for use in rigid PVC foam.

\section{Recycling}

PVC foam is a particularly good application into which recycled polymer can be accepted. Recycled PVC can easily be incorporated into the core of co-extruded PVC foam profile or pipe, with the skin layers being virgin PVC. The recyclate may be industrial scrap recovered from pipe production or foam production processes, or it may be material recovered after consumer use. There have been a number of initiatives to use postconsumer PVC recyclate in co-extruded foamed products. For example, waste PVC pipes and fittings are used in the co-extrusion of non-pressure sewage pipe [14]. It has also been demonstrated that recycled PVC packaging is suitable for use as the foamed core in co-extruded cellular profiles for building applications $[15,16]$.

\section{Composites with Wood Flour}

There is growing commercial interest in wood-flour filled thermoplastic composites. These materials have the aesthetic characteristics of wood with the processing characteristics of thermoplastics, and offer a way of lowering raw material costs. They are environmentally friendly in that they utilise both scrap sawdust and, in many cases, recycled thermoplastics as well. Although the vast majority of these products are based on polyolefins, there is significant usage of PVC, which has the advantages of better fire resistance and weathering behaviour. The higher surface energy of PVC means that PVC wood-flour products can be painted or stained without the need for additional surface treatment.

A disadvantage of using wood flour is its high moisture content, which in solid products can disrupt thermoplastic processing causing voids and poor surface quality. Foaming of these products therefore offers a numbers of advantages. Foaming with chemical blowing agents has been used to reduce the specific gravity of PVC wood-flour composites to make these products more comparable to wood [17]. A further development is to use the moisture contained in the wood flour as a foaming agent [18]. 


\section{Physical Blowing Agents and Microcellular Foams}

Physical blowing agents are rarely used in the extrusion of foamed PVC, although direct gassing of carbon dioxide and nitrogen should be considerably cheaper than deriving these same gases from chemical blowing agents. Dey and co-workers [19] have reported a novel method of extruding high density, rigid PVC foam using a commercial PVC compound with inert gas $\left(\mathrm{CO}_{2}\right.$ or argon). This process was developed on a segmented single screw extruder with L/D ratio of 40 . Gas was injected into the barrel through a nozzle in a Dynisco type port. Using this set-up they were able to produce free foam rods with densities of the same order as currently produced by conventional technology using chemical blowing agents. It was difficult to get a fine foam structure with $\mathrm{CO}_{2}$ but there was an improvement when talc was added as a nucleating agent.

Direct gas injection of $\mathrm{CO}_{2}$ and $\mathrm{N}_{2}$ is also being used in the emerging technology of microcellular foam extrusion [20].

\section{Nanofillers}

Nanocomposites are a novel class of polymer composite that contain relatively small amounts (typically less than $5 \mathrm{wt} \%$ ) of nanometer-sized filler particles. The fillers may be natural or synthetic clays, platelets, spheres, tubes, fibres or sol-gel particles: all characterised by having at least one dimension in the nanometer range. These materials are considered to be of great scientific importance and it is expected that they will find significant use in many technological applications. The intense interest in polymer nanocomposites is based on their potential to bring about a step change in properties.

As in the case of other thermoplastics, nanocomposite technology appears to have the potential to create a step change in properties for PVC. Apart from enhanced mechanical properties, a well-dispersed nanofiller could bring improvements in heat distortion temperature, gas barrier, fire retardancy and heat stability. It is possible that nanofillers could be used to address some of the sustainability issues facing PVC [21]: perhaps to create a new generation of thermal stabilisers or smoke suppressants, or to help prevent the leaching out of plasticisers. They also have interesting possibilities for use in rigid PVC foams, as either novel heat stabilisers, or as nucleating agents.

\section{CONCLUSIONS}

Cellular PVC-U is a well-researched material with a growing global market. There is still much opportunity for developing novel applications for wood-replacement products and for finding new ways of foaming solid products to improve cost effectiveness. Apart from the challenge of product innovation, there is also the challenge of environmental sustainability. Particular issues are the replacement of lead stabilisers and the enhancement of end-of-life product recycling. Novel chemicals such as organic based stabilisers and nanofillers also offer the potential to tackle sustainability issues and help to create the next step change in properties.

\section{REFERENCES}

1. Allsopp, M. W. (1982) Chapter 8 Mechanism of Gelation of Rigid PVC in Manufacture and Processing of PVC, Ed., Burgess, R. H. pp 183-213, Elsevier Applied Science Publishers, London.

2. Summers, J. W. (1981) The Nature of PVC Crystallinity: The Microdomain Structure, Journal of Vinyl Technology, 3(2):107-110.

3. Schneider H.P. (1997) Chapter 13 Extrusion of Foamed Semi-finished Products with Twin-Screw Extruders in Plastics Extrusion Technology, 2nd Edition, Ed., Hensen, F. pp 435-454, Hanser Publishers, Munich, Germany.

4. Thomas, N.L. (1998) Cellular UPVC: Principles and Applications, Progress in Rubber and Plastics Technology, 14(3): 129-150.

5. Collington, K. (1991) Chemical Expansion Systems, Proceedings of Cellular Polymers I, Paper No.22, Rapra Technology Ltd., Shrewsbury, UK.

6. Beckmann, G. (1987) Extrusion and Properties of Cellular and High Impact uPVC Profiles for the Building Industry, Proc. Conf. PVC '87, Paper 13, PRI, Brighton, UK.

7. Thomas, N.L., Eastup, R.P. and Quirk, J.P. (1997) Aspects of Formulation Technology of Rigid Poly(vinyl chloride) Foam, Plastics, Rubber and Composites: Processing and Applications, 26(2): 47-54.

8. Thomas, N.L. and Harvey, R.J. (1999) Statistical Experimental Design to Optimize Formulations for Foam Vinyl Applications, Journal of Vinyl and Additive Technology, 5(2): 63-70.

9. Szamborski, G. and Pfennig, J-L. (1992) Formulating Technology for Rigid Cellular PVC Sheet, Journal of Vinyl Technology, 14(2): 105-109. 
10. Ide, F. and Okano, K. (1981) Effects of Blending Acrylic Polymers on the Physical Properties and Processing Behaviour of Poly(Vinyl Chloride), Pure \& Applied Chemistry, 53: 489-499.

11. Haworth, B., Chua L. and Thomas, N.L. (1994) Elongational Deformation and Rupture of Rigid PVC Compounds for Foam Extrusion, Plastics, Rubber and Composites Processing and Applications, 22(3): 159-169.

12. www.vinyl2010.com

13. Hopfmann, T. (2002) Organic Based Stabiliser System - Commercial Introduction, Proceedings of PVC 2002 Conference, pp 515-528, IOM Communications, $23^{\text {rd }}-25^{\text {th }}$ April 2002, Brighton, UK.

14. Dupont, S., Dehennau, C., Benjamin, P., Rijpkema, B. and Voituron, G. (1991) The Use of PVC Bottle Scraps in Coextruded Light Weight PVC Sewage Pipes, Proceedings of $4^{\text {th }}$ International Conference Recycle'91, pp 7.1-7.24, $3^{\text {rd }}-5^{\text {th }}$ April 1991, Davos, Switzerland.

15. Thomas, N.L. and Quirk, J.P. (1995) Use of Bottle Recyclate in Rigid PVC Foam, Plastics, Rubber and Composites Processing and Applications, 24(2): 89-96.

16. Thomas, N.L., Quirk, J.P. and Cretney, H.(1997) Recycling of PVC Supermarket Trays into Rigid Foam Extrusions, Progress in Rubber and Plastics Technology, 13(1): 56-76.

17. Patterson, J. (2001) New opportunities with wood-flour-foamed PVC, J. Vinyl \& Additive Technol., 7 (3): 138-141.

18. Matuana, L. M. and Mengeloglu, F. (2002) Manufacture of Rigid PVC/Wood-Flour Composite Foams Using Moisture Contained in Wood as Foaming Agent, J. Vinyl \& Additive Technol., 8 (4): 264-270.

19. Dey, S. K., Jacob, C. and Xanthos, M. (1996) Inert-gas extrusion of rigid PVC foam, J. Vinyl \& Additive Technol., 2 (1): 48-52.

20. Holl, M.R., Ma, M., Kumar, V. and Kwapisz, R.R. (1998) The Effect of Additives on Microcellular PVC Foams: Part I - Effect on Processing and Microstructure, Cellular Polymers, 17(4), 271.

21. www.vinylsum.org.uk 
Tables

\begin{tabular}{|c|c|c|c|}
\hline Polymer & $\mathrm{Tg}^{\circ} \mathrm{C}$ & $\mathrm{Tm}^{\circ} \mathrm{C}$ & $\operatorname{Tdeg}^{\circ} \mathrm{C}$ \\
\hline LDPE & -60 & 112 & 300 \\
\hline HDPE & -35 & 133 & 330 \\
\hline PP & 10 & 170 & 330 \\
\hline PS & 100 & $\mathrm{~N} / \mathrm{a}$ & 300 \\
\hline Nylon 6 & 90 & 265 & 310 \\
\hline UPVC & 80 & $>200$ & 200 \\
\hline UPVC (stabilised) & 80 & $>200$ & \\
\hline
\end{tabular}

Table 1. Processing Window of Thermoplastics

\begin{tabular}{|c|c|}
\hline Ingredient & Parts per hundred parts of polymer (phr) \\
\hline PVC - resin (K57 - K60) & 100 \\
\hline Tin stabiliser & $1.0-2.0$ \\
\hline Epoxy compound (co-stabiliser) & $1.0-2.0$ \\
\hline Lubricants (internal and external) & $1.5-2.5$ \\
\hline Acrylic processing aid & $6-10$ \\
\hline Blowing agent (ADC) & $0.4-0.8$ \\
\hline Pigment (as required) & $1-5$ \\
\hline Filler (calcium carbonate) & $4-8$ \\
\hline
\end{tabular}

Table 2. Guideline Tin-stabilised Formulation for Rigid Foam Sheet

\begin{tabular}{|c|c|}
\hline Ingredient & Parts per hundred parts of polymer (phr) \\
\hline PVC - resin (K57 - K60) & 100 \\
\hline Ca/Zn stabiliser & $1.0-2.0$ \\
\hline Co-stabiliser & $1.0-2.0$ \\
\hline Lubricants (internal and external) & $1.0-1.5$ \\
\hline Acrylic processing aid & $5-8$ \\
\hline Blowing agent (SBC \& ADC) & $1.5-2.5$ \\
\hline Pigment (as required) & $1-5$ \\
\hline Filler (calcium carbonate) & $4-8$ \\
\hline
\end{tabular}

Table 3. Guideline Ca/Zn-stabilised Formulation for Rigid Foam Profile 


\section{Figures}

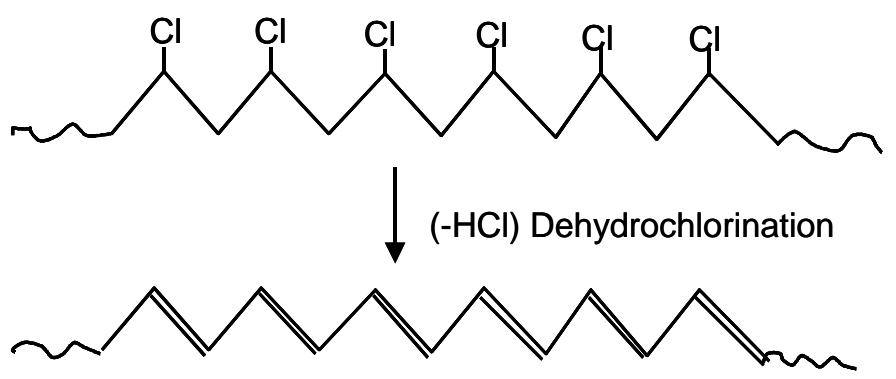

Figure 1. Thermal Degradation of PVC

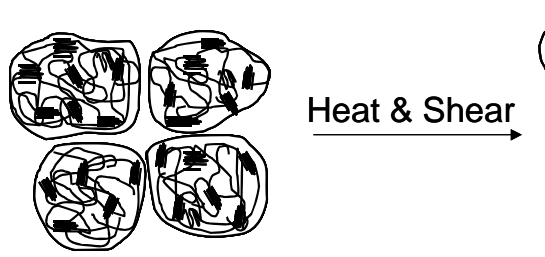

A

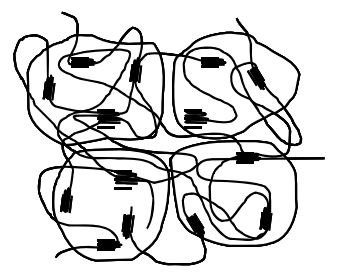

B

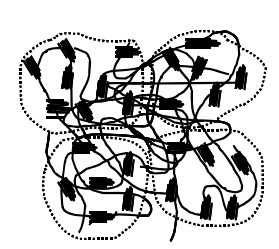

Cooling

C

Figure 2. Fusion of Primary Particles of PVC 


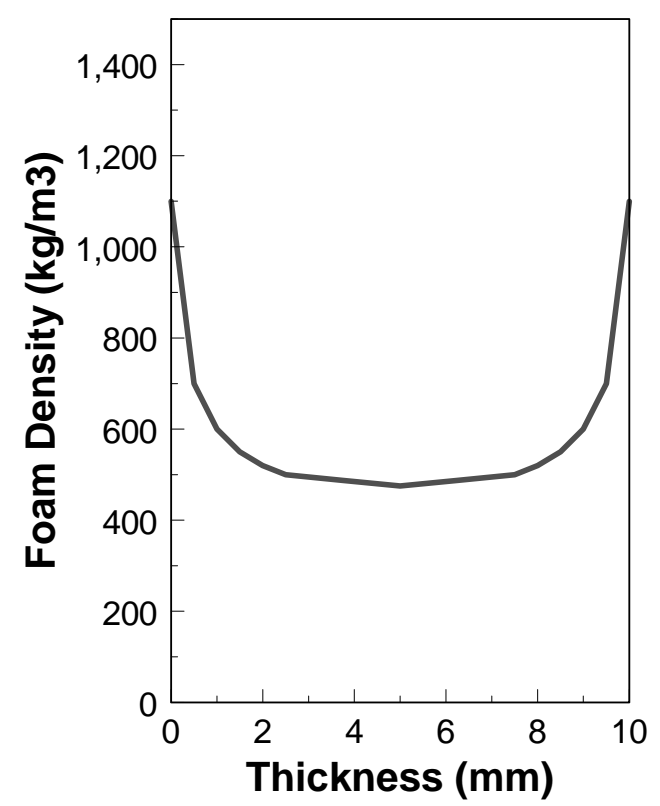

Figure 3. Density Distribution across Free-foam Sheet

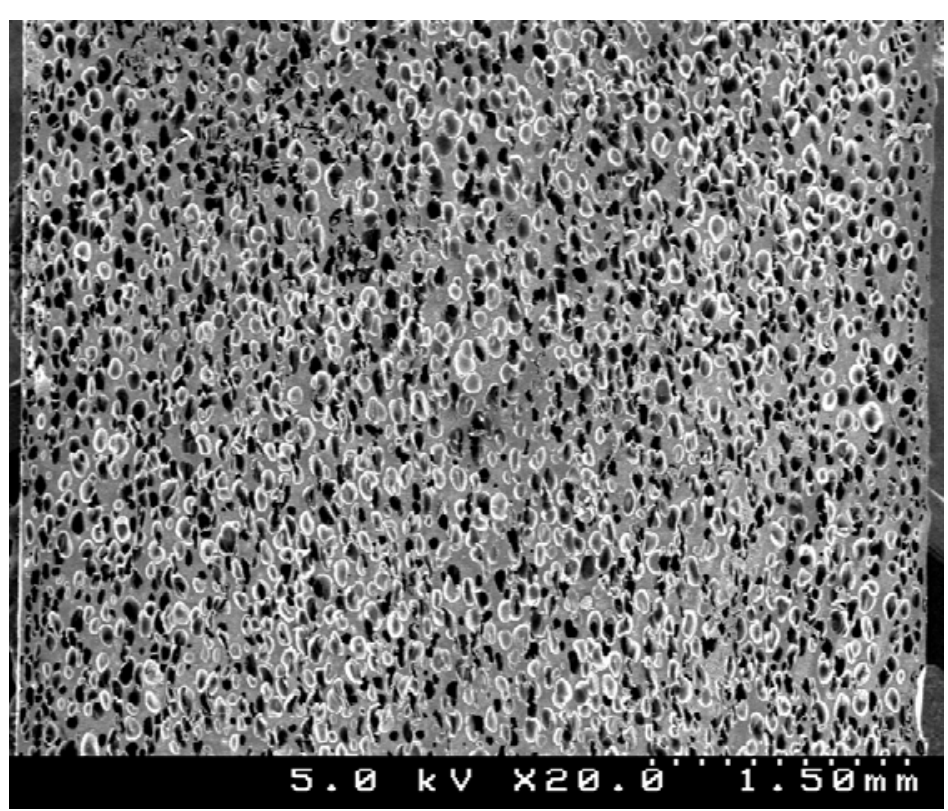

Figure 4. SEM of Cross-section through Free-foam Sheet 


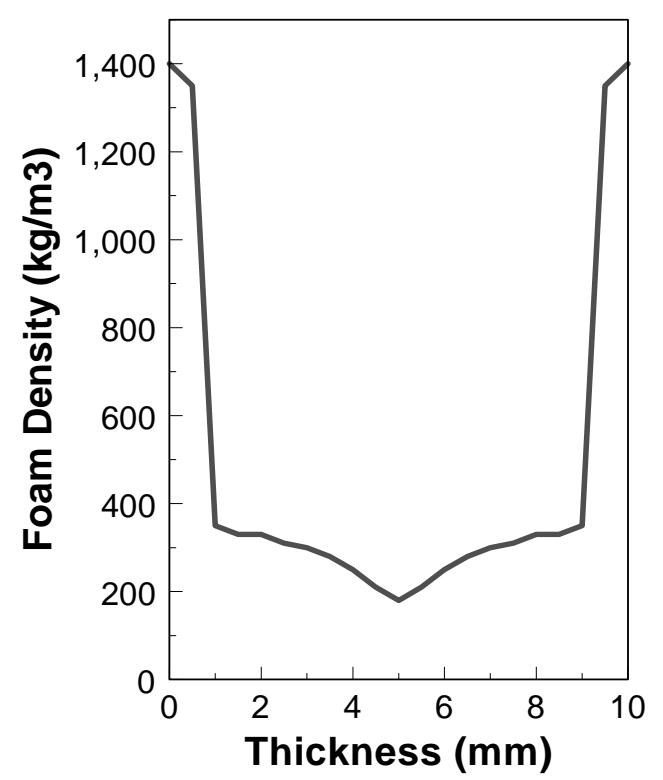

Figure 5. Density distribution across Celuka Profile

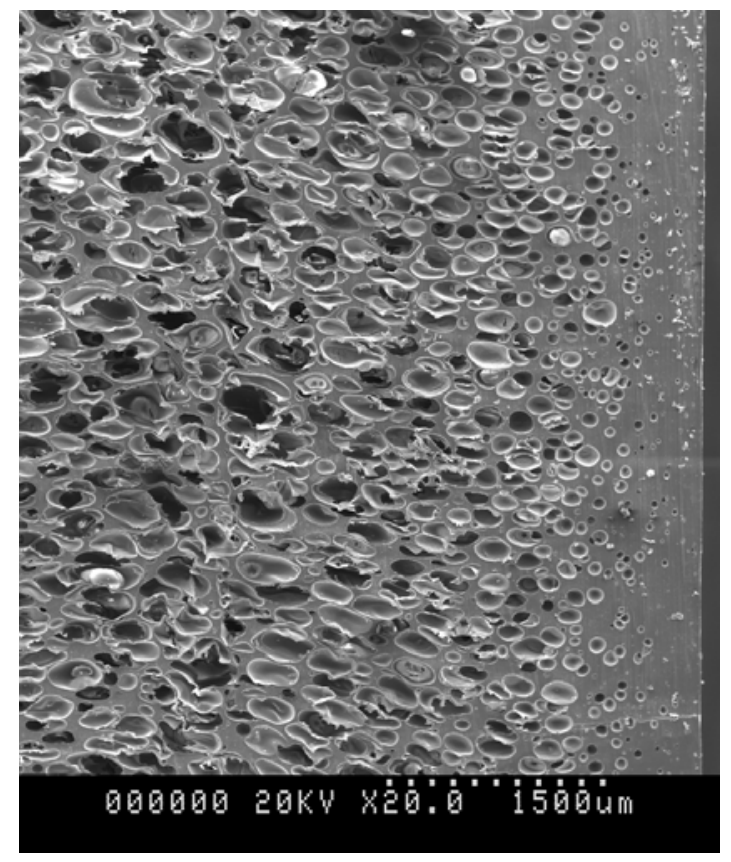

Figure 6. SEM of Cross-section through Celuka Profile 


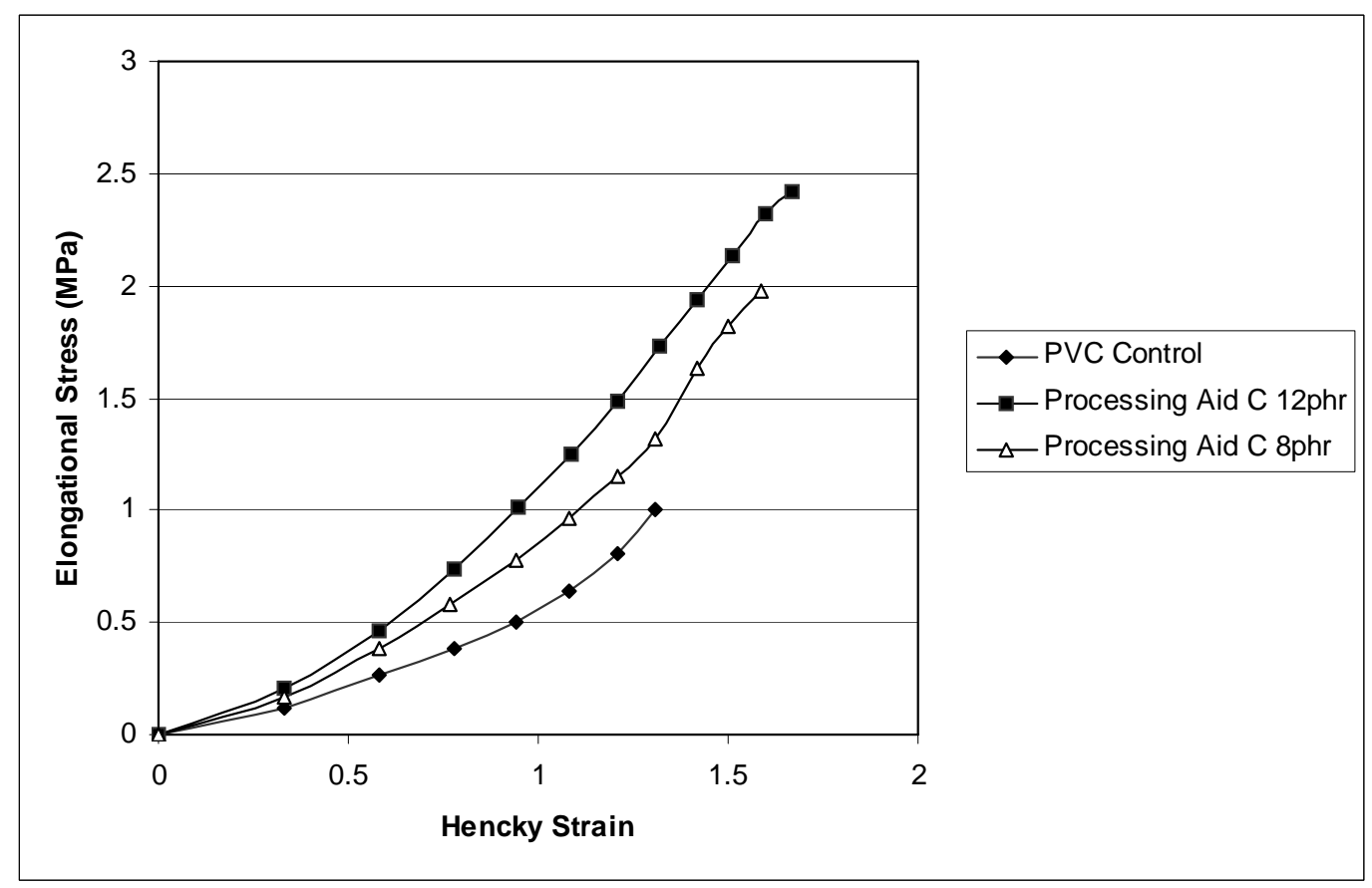

Figure 7. Effect of Processing Aid Addition Level on the Elongational Deformation Behaviour of PVC

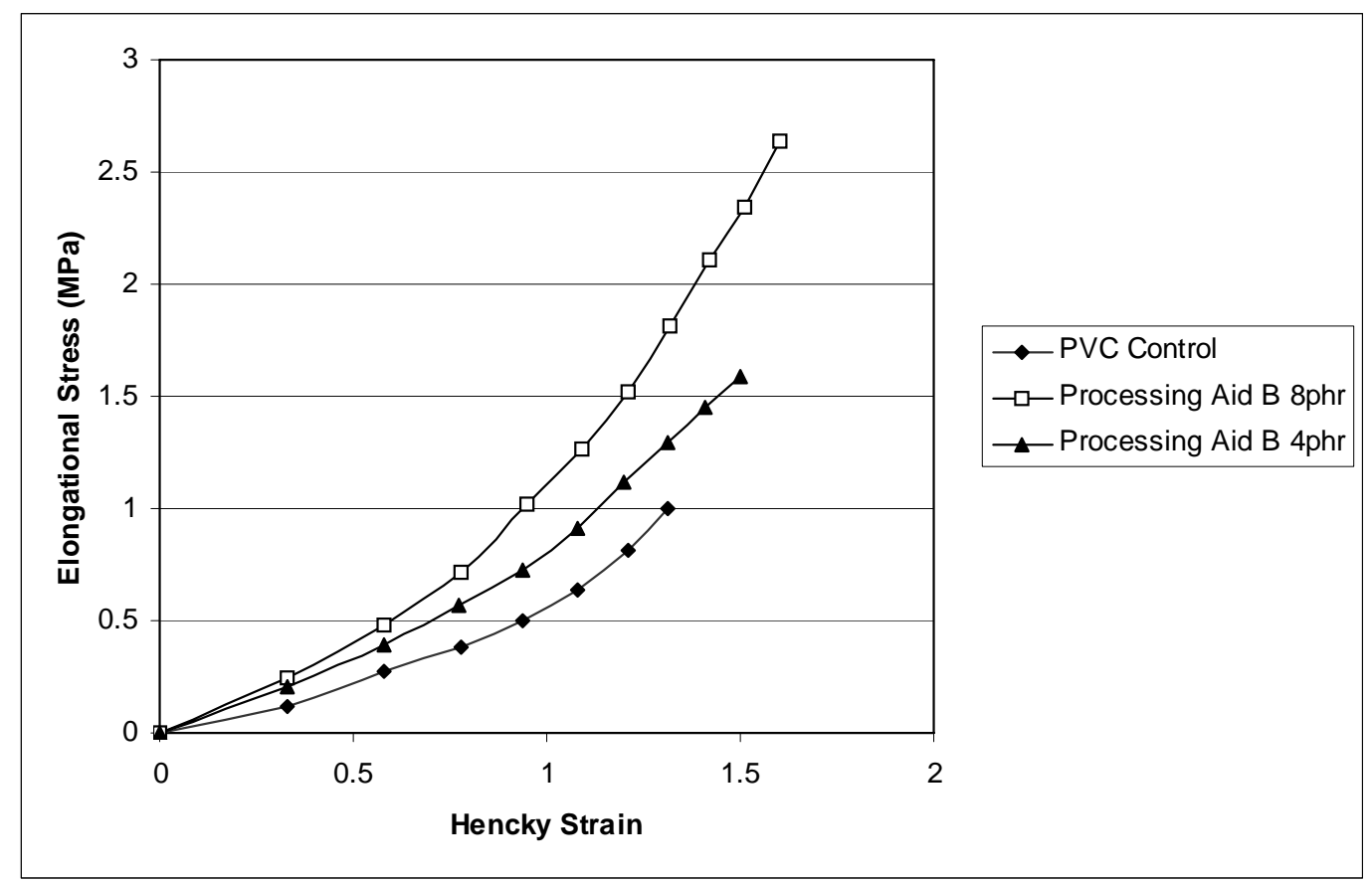

Figure 8. Effect of Processing Aid Addition Level on the Elongational Deformation Behaviour of PVC 


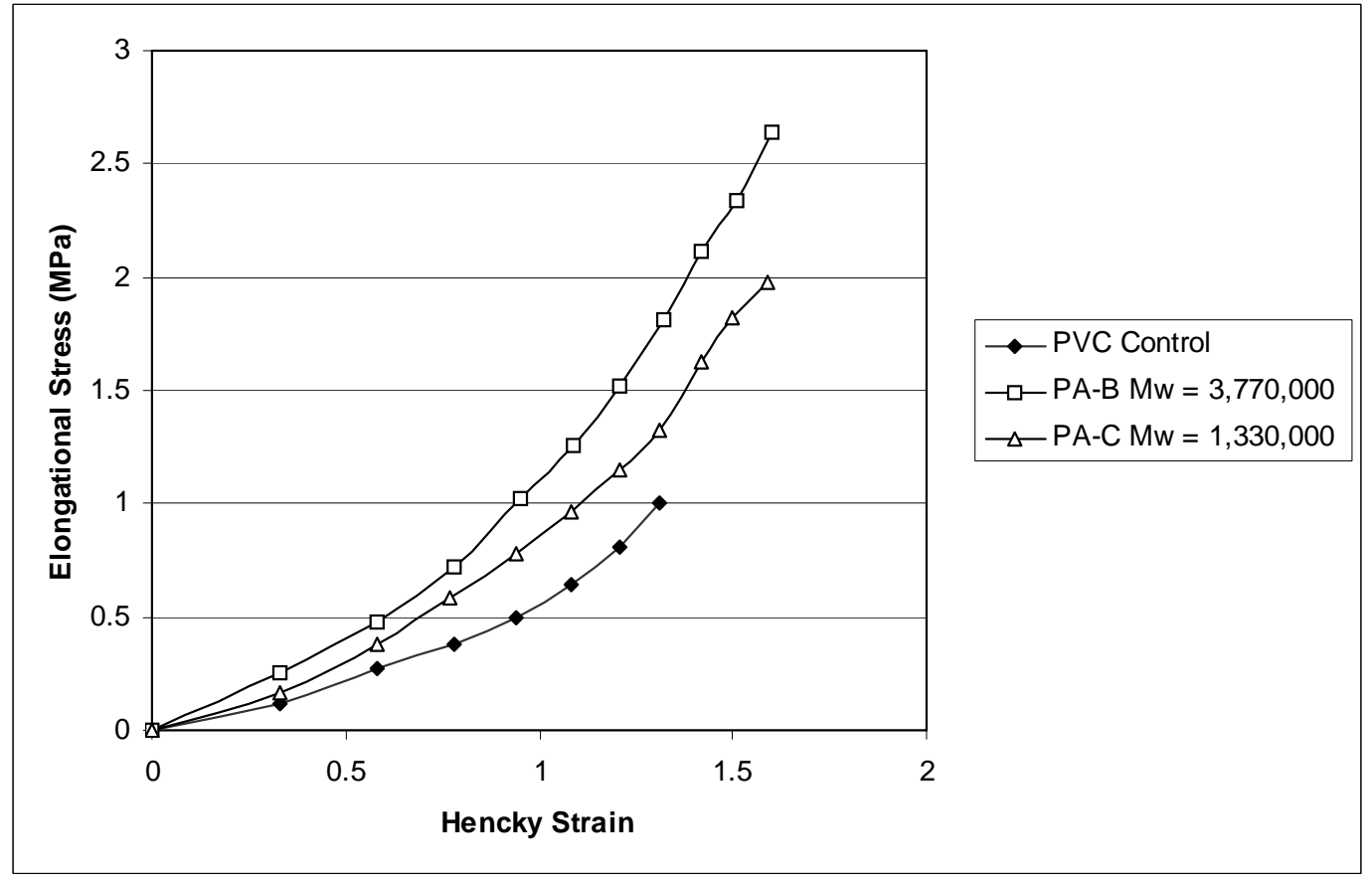

Figure 9. Effect of Processing Aid Molecular Weight on the Elongational Deformation Behaviour of PVC

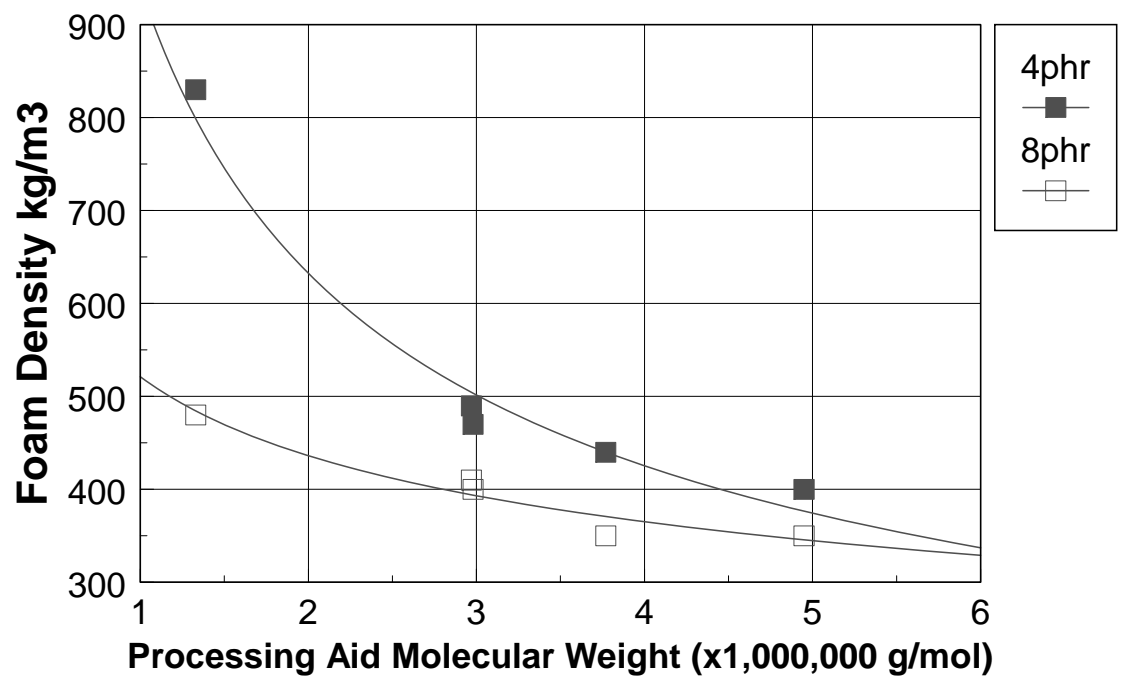

Figure 10. Effect of Processing Aid Molecular Weight and Level on Foam Density 


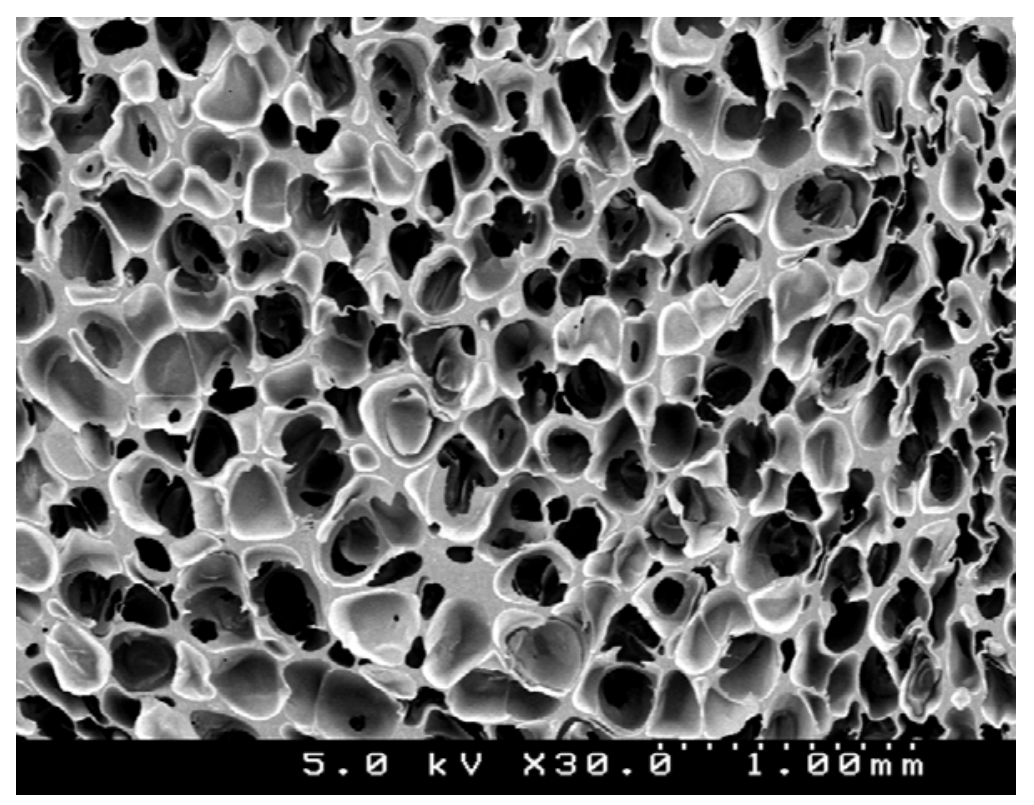

Figure 11. Low Density Foam with 8phr of Processing Aid

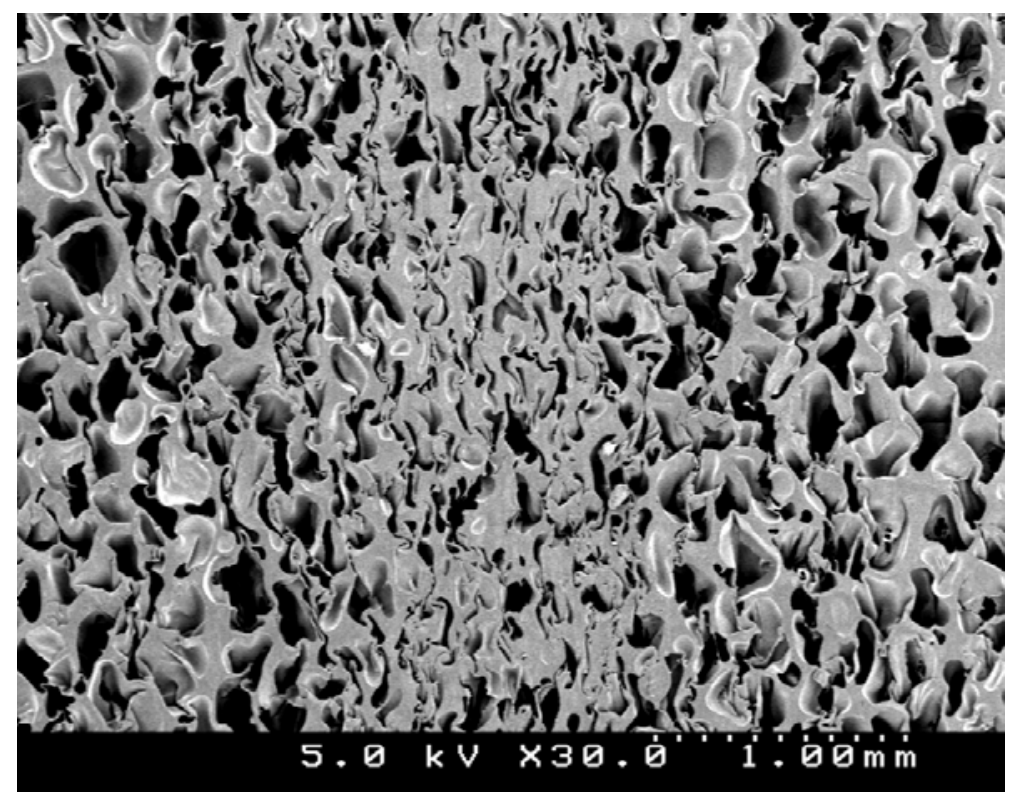

Figure 12. Reduced Processing Aid Level gives Cell Collapse 


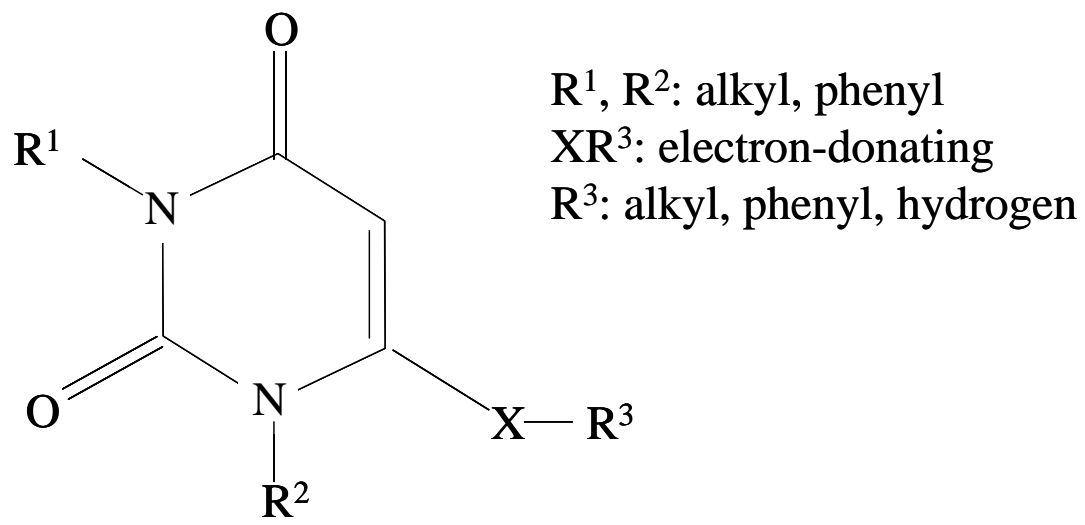

Figure 13. Chemical Structure of OBS Systems 